\title{
Forgiving Significant Interpersonal Offenses: The Role of Victim/Offender Racial Similarity*
}

\author{
Courtney Cornick ${ }^{1}$, Jessica M. Schultz ${ }^{2}$, Benjamin Tallman ${ }^{3}$, \\ Elizabeth M. Altmaier, \\ ${ }^{1}$ Department of Psychological and Quantitative Foundations, University of Iowa, Iowa City, USA; \\ ${ }^{2}$ Department of Psychology, Augustana College, Rock Island, USA; \\ ${ }^{3}$ Edward Hines Jr. VA Hospital, Chicago, USA; \\ ${ }^{4}$ Department of Community and Behavioral Health, University of Iowa, Iowa City, USA. \\ Email: Elizabeth-altmaier@uiowa.edu \\ Received August 17 $7^{\text {th }}, 2011$; revised September 20 $0^{\text {th }}, 2011$; accepted October $22^{\text {nd }}, 2011$.
}

\begin{abstract}
The influence of victim/offender racial similarity on victim forgiveness was investigated in a study of interpersonal transgressions. It was hypothesized that racial similarity between victim and offender would influence forgiveness only for transgressions that were less distressing for the victim. Participants were 104 adults (45 Black and 59 White) who provided a narrative description of a significant interpersonal transgression they had experienced and completed measures of transgression-related distress and forgiveness. Forgiveness was measured as positive (benevolence) and negative (revenge, avoidance) motivations toward the offender. For negative motivetions, revenge and avoidance, there was no effect of racial similarity: more severe distress was associated with less forgiveness for all victim/offender pairings. However, the results revealed a significant interaction of victim/offender racial similarity and distress for positive motivations: Black victims reported increased benevolence towards Black offenders after more distressing transgressions. Victims in other racial combinations reported reduced benevolence for more distressing transgressions. In group favoring of Black offenders by Black victims may be an unexplored aspect of forgiveness. Little research has addressed the potential influence of context on interpersonal forgiveness, and this study suggests that these influences may play an important role.
\end{abstract}

Keywords: Forgiveness, Race, Cultural Psychology, Counseling

\section{Introduction}

McCullough et al. (1998) defined forgiveness in motivational terms: the victim releases negative motivations (e.g., revenge) towards the offender and assumes positive motivations (e.g., goodwill) in the aftermath of an interpersonal transgression. Similarly, Enright and Fitzgibbons (2000) suggest that forgiveness involves the victim overcoming negative affect and judgment towards the offender and instead viewing him or her with empathy or compassion.

However, it is important to consider forgiveness in a larger context than that encompassing solely two people, particularly when a larger perspective suggests societal or contextual influences on a victim's forgiveness response. For example, Digeser (2001) argued that oppressed groups experience a historical burden of transgressions. Thus, forgiveness may be more difficult for oppressed persons than for persons with a history of privilege. This difficulty may be especially present in personto-person forgiveness when the offender has a history of privilege and the victim has a history of oppression. Race is an area of clear differences between groups in terms of privilege and oppression.

Unfortunately, little is known about the role of race in forgiveness. Erguner-Tekinalp (2007) studied Black college students' perceptions of historical racism and personally experienced racially offensive acts. When Black students perceived societal remorse and motivations for reparation, they reported more forgiveness of historical racial transgressions. However,

\footnotetext{
${ }^{*}$ This research was supported in part by a Summer Research Opportunity Fellowship awarded to the first author by the Committee on Institutional Cooperation.
}

these societal influences did not predict forgiveness for personally experienced acts. When the context of racial similarity of victim to offender is taken into account, forgiveness may be altered. Miller (2001) summarized research that suggests a victim will find an offender's action more disrespectful if the offender belongs to the same social group as the victim.

Distantly related research that explores whether culturally different groups are able to forgive one another is relevant to the current study. One of the primary examples of intergroup forgiveness was the Truth and Reconciliation Commission of South Africa. This commission was created to assist with reparation to, and the rehabilitation and restoration of human and civil dignity of, victims of violations of human rights following the Promotion of National Unity and Reconciliation Act in 1995. Research following the actions of the Commission demonstrated that even in the context of profoundly severe transgressions, such as murder and torture, victims of one race were able to forgive offenders of another (Kaminer, Stein, Mbanga, \& Zungu-Dirwayi, 2001; Stein et al., 2008).

Forgiveness is predicted by many factors. For example, having an offender apologize for the transgression is positively related to the victim forgiving him or her (Girard, Mullet, \& Calahan, 2002). Transgression severity is also related to forgiveness, with more severe transgressions predicting less forgiveness. However, researchers have not analyzed the role of racial similarity versus dissimilarity. The above discussion suggests that people of varying races are able to forgive each other, although the influence of past historical wrongs may continue. If one considers research on racial micro aggressions (see Sue et al., 2007) in combination with privilege and oppression, it would be reasonable to expect that a transgression 
committed by a White offender would have a more negative effect on a Black victim than if committed by a Black offender.

The current study examined forgiveness as a function of the racial similarity of the victim and the offender. There were two objectives for the study. First, is forgiveness affected by whether the race of the victim is the same or different from that of the offender? Second, does the impact of the transgression moderate any relationship between racial difference and forgiveness? Based on previous research, the hypothesis was that more severe distress would be associated with less forgiveness.

\section{Method}

\section{Participants}

Participants were adults from four cities who volunteered based on advertisements posted in community locations. Data for the current study were taken from a larger study of the relationship of forgiveness to posttraumatic growth (Schultz, Tallman, \& Altmaier, 2010) and consisted of those Black and White victims who identified their offender as Black or White. The sample consisted of 104 persons. There were 57 females and 47 males; their average age was 41.67 years, $S D=13.58$. Demographic characteristics of the sample are presented in Table 1.

Most participants identified a religious affiliation, and the majority of those were a Christian denomination. Educational

Table 1.

Demographic characteristics.

\begin{tabular}{|c|c|c|}
\hline Characteristic & $n$ & $\%$ \\
\hline \multicolumn{3}{|l|}{ Gender } \\
\hline Male & 47 & 45.2 \\
\hline Female & 57 & 54.8 \\
\hline \multicolumn{3}{|l|}{ Race/ethnicity } \\
\hline White & 59 & 56.7 \\
\hline Black & 45 & 43.3 \\
\hline \multicolumn{3}{|l|}{ Religious affiliation } \\
\hline Protestant & 34 & 33.0 \\
\hline Catholic & 13 & 12.6 \\
\hline Christian & 14 & 13.6 \\
\hline Spiritual & 11 & 10.7 \\
\hline None & 25 & 24.3 \\
\hline Other & 6 & 5.7 \\
\hline \multicolumn{3}{|l|}{ Educational level } \\
\hline Below high school & 8 & 7.7 \\
\hline Some high school & 47 & 45.2 \\
\hline Some college & 28 & 26.9 \\
\hline College degree & 12 & 11.5 \\
\hline Graduate/professional degree & 9 & 8.7 \\
\hline \multicolumn{3}{|l|}{ Marital status } \\
\hline Single/never married & 52 & 50.5 \\
\hline Married/cohabitating & 16 & 15.6 \\
\hline Separated/divorced & 28 & 27.2 \\
\hline Widowed & 6 & 5.8 \\
\hline Other & 1 & 1.0 \\
\hline
\end{tabular}

Note: Not all participants answered all questions. background was diverse: equal numbers reported a graduate/ professional degree as reporting education below high school; one-third of the sample had enrolled in college. Approximately half the sample reported being single or never having married.

\section{Procedure}

Institutional Review Board approval for the following procedure was obtained. Flyers inviting participation in a research study about being "significantly wronged" by another person were posted in businesses and community centers in four metropolitan areas in the state in which the study was conducted. The invitation directed potential participants to call a telephone number for more information. When the telephone was not personally answered, a voice message directed participants to leave contact information or to return the call at certain hours. During the telephone call, participants were informed about the study and screened for three criteria: age between 18 and 75, the transgression was not ongoing, and the transgression had occurred no more than five years before. Participants were then signed up for data collection at particular times at community sites.

Upon arrival at the site, participants were provided with informed consent and then completed study measures. Researchers (Black and White) were available at each site to answer questions and monitor participants' apparent state of distress. Afterwards, participants were given $\$ 20$ for their participation and were provided with a list of local mental health resources (including low cost and no cost services).

\section{Measures}

\section{Demographic Variables}

Participants provided information on demographic variables: age, gender, race, employment status, marital status, educational status. Participants also provided as much parallel information as possible concerning the offender. The participant wrote a narrative description of the transgression, coded by raters for type of transgression (see Schultz et al., 2010 for additional details on coding process) The types of transgresssions experienced were sexual assault, physical assault, infidelity, theft or damage of property, slander, betrayal, and lies.

\section{Distress}

The Impact of Event Scale-Revised (IES-R; Weiss \& Marmar, 1997) assesses subjective distress related to a specific life event and was used as a measure of distress caused to the participant by the transgression. The IES-R consists of 22 items. Directions, which usually ask participants to rates distress experienced during the previous 7 days, were modified to assess the highest distress caused by the transgression. Item responses range from 0 (not at all) to 4 (extremely); higher scores reflect increased levels of distress, and the total score can range from 0 to 88. Examples of items include "Pictures about it popped into my mind" and "I felt irritable and angry". The IES-R was validated with two groups of persons: emergency personnel exposed to a freeway collapse and responders to an earthquake. Coefficient alpha for the total score was previously reported at .96 .

\section{Forgiveness}

Interpersonal forgiveness was measured by the Transgression-related Interpersonal Motivations Inventory-18 (TRIM-18; McCullough et al., 1998; McCullough, Root, \& Cohen, 2006). The TRIM-18 has three scales: Avoidance (seven items; e.g. "I withdraw from him/her"), Revenge (five items; e.g. "I'll make 
him/her pay"), and Benevolence (six items; e.g. "Even though his/her actions hurt me, I have goodwill for him/her"). Participants used a five-point response scale $(1=$ strongly disagree to $5=$ strongly agree). The three subscales of the TRIM-18 have demonstrated internal consistency $(\alpha>.85)$ and test-retest stability $(r \approx .50)$. McCullough et al. (1998) provided validity information on the measure's significant correlation with quality and closeness of interpersonal relationships.

\section{Results}

Data were analyzed using the SPSS program. Table 2 presents means, standard deviations, and possible score range for study variables as well as coefficient alpha (scale reliability) and scale inter-correlations. The first research question addressed differences in forgiveness as a function of racial similarity between victim and offender. Four dyads were constructed based on offender race and participants' race: White offender/White victim $(n=53)$; Black offender/White victim ( $n$ $=6)$; White offender/Black victim $(n=8)$; and Black offender/Black victim $(n=37)$. Based on the dyads, three dummy variables were created for the regression models. White offender/White victim served as the baseline group (coded as 0 ) to which the other three groups were compared (coded as 1). Before regressions were conducted, assumptions were examined including normality (e.g., skewness and kurtosis) and outliers. Frequency distributions and scatter plots revealed that continuous variables did not significantly deviate from normality; thus, the original data were retained. The racial difference variables were entered into the first block, distress (measured by the IES-R total) in the second block to control for variability in forgiveness related to the transgression itself, and three interaction terms between racial difference and distress in the third block.

Three separate hierarchical regressions were conducted with TRIM-18 subscales-Avoidance, Revenge, and Benevolenceas dependent variables. In regression models with avoidance and revenge as dependent variables, interaction terms were not significant; distress did not moderate the relationships between racial similarity and motivations for avoidance and revenge. The simpler model of racial similarity and distress predicting forgiveness scales was then considered. In this model, racial similarity was held constant, and the effect of distress on forgiveness was examined. Distress was positively related to revenge $(B=.21, p<.05)$ and avoidance $(B=.22, p<.05)$ after controlling for racial similarity.

In the regression model for benevolence as a dependent variable, a significant interaction emerged between benevolence and the third dummy variable that was coded as Black offender/Black victim $(B=.963, p<.001)$. The relationship between racial similarity and benevolence thus depends upon the psychological impact of the event. The slopes of the four dyads were graphed to determine the nature of the significant interaction. See Figure 1. Regression slopes for three dyadsWhite offender/White victim, Black offender/White victim, White offender/Black victim — appeared similar; therefore, nonsignificant dummy variables were reexamined in the regression analysis. No significant findings emerged for the dummy variables. To increase statistical power two dyads were combined to create a new dummy variable. The Black offender/ Black victim dyad was coded as 1 ; the other three groups as 0 . As in the previous regression model, the new dummy variable was entered in the first block, distress in the second, and an interaction term in the third block. The interaction between distress and racial similarity/dissimilarity was significant $(B=$ $1.02, p=.000$ ). See Table 3 for regression coefficients.

When a moderated effect is present, it is important to describe the nature of the interaction (Hayes \& Matthes, 2009). A common approach to examining moderated effects is the pick-a-point approach. This approach relies on arbitrarily picking points on the moderator variable at the mean and one standard deviation above and below the mean (Bauer \& Curran, 2005). Confidence intervals are constructed to determine if the independent variable is statistically significant at the chosen points on the moderated variable. The Johnson-Neyman (J-N; Johnson \& Neyman, 1936) technique is a more precise method of examining moderated effects, within linear models, and removes the arbitrariness associated with the pick-a-point approach. The J-N technique creates confidence bands around simple slopes of regression lines and provides a visual representation, or a region of significance, of the effect of the independent variable across values of the moderator variable. Confidence bands are used to derive a point or points along a continuum at which the moderated variable is statistically signifycant.

The SPSS macro developed by Hayes and Matthes (2009) was used to examine the moderated effects using the J-N technique. Ninety-five percent $\mathrm{J}-\mathrm{N}$ confidence bands were constructed for the impact of event. The confidence band for the lower limit was 23.52 and the upper limit was 47.63. Scores that fall outside the range $23.52 \leq \mathrm{x} \leq 47.63$ are significant. We also examined the simple slopes of racial difference as a dichotomous moderator variable. The simple slope for Black perpetrator/Black victim dyad was -.159 (LLCI $=-.2483$, ULCI $=-.0699, p=.000)$. The simple slope for the combined racial dyad group was $.1288(\mathrm{LLCI}=.0047$; ULCI $=.2527, p=.04)$.

As a general statement, results revealed that Black victims were more forgiving of Black offenders (reported more benevolence) when the transgression was more distressing than less distressing; for all other racial combinations, the reverse was true, that victims were less forgiving of offenders when the

Table 2.

Descriptive statistics and correlations of study variables.

\begin{tabular}{lcccccccc}
\hline \multirow{2}{*}{ Variable } & \multicolumn{9}{c}{ Correlations } & \multirow{2}{*}{ M } & SD & $\alpha$ & Range \\
\cline { 2 - 5 } & 1 & 2 & 3 & 4 & & & & \\
\hline 1. Distress & - & $.23^{*}$ & $.21^{*}$ & -.14 & 44.8 & 17.5 & .92 & $0-88$ \\
2. Avoidance & $.23^{*}$ & - & $.43^{* * *}$ & $-.51^{* *}$ & 22.9 & 7.2 & .79 & $7-35$ \\
3. Revenge & $.21^{*}$ & $.43^{* * *}$ & - & $-.45^{* *}$ & 12.0 & 5.3 & .82 & $5-25$ \\
4. Benevolence & -.14 & $-.51^{* *}$ & $-.45^{* *}$ & - & 16.8 & 7.0 & .84 & $6-30$ \\
\hline
\end{tabular}

Note: Correlations are zero order; ${ }^{*} p<.05 .{ }^{* *} p<.001$. 
Table 3.

Regression coefficients for forgiveness (Benevolence).

\begin{tabular}{lccc}
\hline Predictor variable & B & SEB & $\beta$ \\
\hline Model 1 & & & \\
Black offender/White victim (BW) & .128 & 7.84 & 3.79 \\
White offender/Black victim (WB) & -.031 & 10.05 & -.814 \\
Black offender/Black victim (BB) & $-.736^{*}$ & 3.92 & -10.63 \\
Distress (D) & $-.362^{*}$ & .05 & -.143 \\
BW $\times$ D & -.194 & .149 & -.108 \\
WB $\times$ D & -.012 & .209 & -.007 \\
BB $\times$ D & $.963 * *$ & .081 & .272 \\
Model 2 & & & \\
Constant & & 2.127 & 23.112 \\
Black offender/Black victim (BB) & $-.756^{*}$ & 3.76 & -11.055 \\
Distress (D) & $-.401 * *$ & .045 & -.159 \\
BB $\times$ D & $1.020^{* *}$ & .077 & .288 \\
\hline
\end{tabular}

Note: For Model $1, R^{2}=.16(p<.01)$; for model $2, R^{2}=.16(p<.001)$; For Model $1, \mathrm{BW}, \mathrm{WB}$, and BB were coded as 1 ; White offender/White victim (coded as 0 ) was the baseline group to which the three other groups were compared. For Model 2 , BB was coded as 1 and the other groups were coded as $0 ;{ }^{*} p<.01 .{ }^{*} p<.001$.

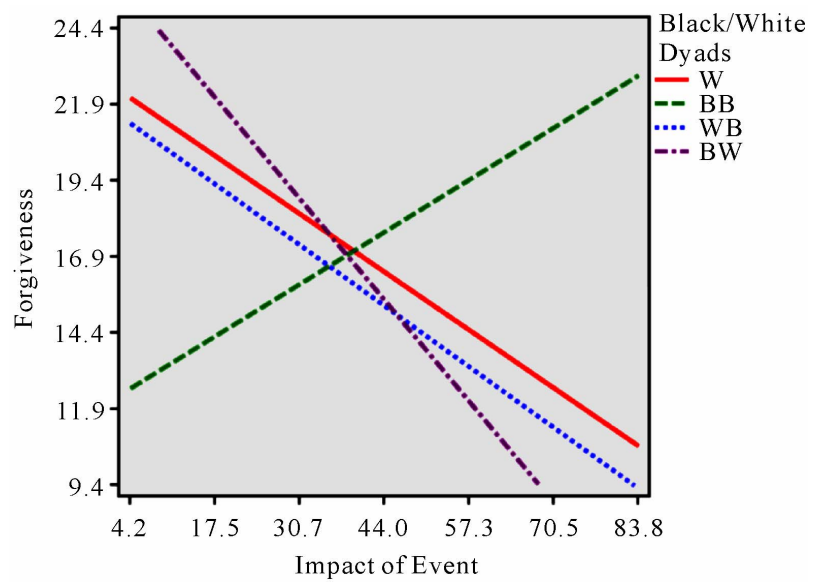

Figure 1.

Graph of regression slopes for racial similarity/dissimilarity dyads. $W W=$ White offender $/$ White victim. $B B=$ Black offender/Black victim. $W B=$ White offender/Black victim. $B W=$ Black offender/White victim.

transgression was severe. For the negative forgiveness variables of revenge and avoidance, there were no effects of racial similarity: all victims reported more revenge and avoidance when the transgressions were more severe.

\section{Discussion}

This research addressed whether being of the same or different race than the offender affected victim forgiveness, and whether any influence of racial similarity on forgiveness was moderated by the distress caused by the transgression. It is important to note that participants had experienced transgresssions that resulted in significant distress: all categories of transgression were rated as highly distressing with the exception of theft of personal property, which was rated as moderately distressing. The research hypothesis was that less distressing of- fenses would be forgiven more by a victim when the offender was racially similar.

The results confirmed the hypothesis for the forgiveness responses of revenge and avoidance. Both Black and White victims reported more revenge and more avoidance of their offender for more distressing offenses. However, the reverse was demonstrated for the forgiveness response of benevolence: As transgression-related distress increased, benevolence also increased for Black victims of Black offenders. Increased transgression-related distress was related to lower benevolence for all other racial pairings: Black victims and White offenders, White victims and White offenders, and White victims and Black offenders.

Research has been published that is relevant to these findings. Mania (2009) studied Black and White college students' responses to media-publicized transgressions committed by a Black professional athlete and a White professional sport coach and in-group favoring of forgiveness responses for the Black athlete by the Black students were noted. However, transgresssions used in that study were not personally relevant, and forgiveness was measured by only two items. The current data, from adults who had experienced interpersonal transgressions, also support in-group favoring by Black victims.

Why did Black victims report more benevolent motivations for Black offenders during highly distressing events than for transgressions that are less distressing? The conflict perspective in the field of criminology (Johnson, 2006; Quinney, 1970) suggests that Black response to injustice is tempered by recognition that both the criminal justice system and society are associated with out-group prejudice which favors White persons. More recently, Johnson (2008) found that racial differences in support for punitive laws and policies, such as three-strike laws, were partially accounted for by perceived racial bias: Blacks perceived more bias than Whites, and this perceived bias helped explain Blacks' lower support for highly punitive laws.

From another perspective, Witvliet, Knoll, Hinman, and DeYoung (2010) recently demonstrated that empathy for offenders was reported more within compassion-focused reappraisal strategies, which were associated with increased positive emotions and changed EMG and cardiac activity. In the current findings, the negative motivations of forgiveness - revenge and avoidance-were directly related to distress while the positive motivations - benevolence - revealed a moderating effect of racial similarity. It appears that empathy for the offender within this study might have been more triggered when both victim and offender was Black.

The lack of difference between forgiving someone racially similar versus racially dissimilar is encouraging from a social justice perspective. In the literature on the Truth and Reconciliation Commission in South Africa, forgiveness was also demonstrated across racial and cultural groups (Kaminer et al., 2001; Stein et al., 2008). For many, forgiveness is a cultural practice learned through cultural teachings, family, and/or religious doctrine. Recent literature establishes culturally-specific conceptualizations of forgiveness, especially among ethnically-based cultures (e.g., Suwartono, Praswasti, \& Mullet, 2007).

This research has several limitations. First, the transgressions were quite severe, and different conclusions might have been revealed if more "every day" transgressions had been reported. Examples of these every day transgressions are being cut off in traffic by another driver, or being interrupted in conversation. Second, all measures were self-report, and the relationship of 
this self-report to behavior is not certain.

Forgiveness is more than an interesting aspect of life; significant mental and physical health benefits are related to forgiveness (Harris \& Thoresen, 2005; Wade, Worthington, \& Meyer, 2005). Psychological variables associated with race, such as collectivist orientation or religious salience, are important areas to explore with regard to forgiveness. Other variables for future research in this area include one's exposure to different racial groups and forgiveness of racially motivated transgressions such as discrimination. Last, the potential influence of race and other societal and contextual variables in study of forgiveness treatments is also an important area for investigation.

\section{References}

Bauer, D., J., \& Curran, P. J. (2005). Probing interaction in fixed and multilevel regression: Inferential and graphical techniques, Multivariate Behavioral Research, 40, 373-400. doi:10.1207/s15327906mbr4003 5

Digeser, P. (2001). Political forgiveness. Ithaca, NY: Cornell University Press.

Erguner-Tekinalp, B. (2007). Forgiveness of historical and current racial transgressions: A study of intergroup forgiveness among Blacks. Dissertation Abstracts International: Section A. Humanities and Social Sciences, 68.

Enright, R. D., \& Fitzgibbons, R. P. (2000). Helping clients forgive: An empirical guide for resolving anger and restoring hope. Washington, DC: American Psychological Association. doi:10.1037/10381-000

Girard, M., Mullet, E., \& Calahan, S. (2002). Mathematics of forgiveness. American Journal of Psychology, 115, 351-375. doi: $10.2307 / 1423422$

Harris, A. H. S., \& Thoresen, C. E. (2005). Forgiveness, unforgiveness, health, and disease. In E. L. Worthington (Ed.), Handbook of forgiveness (pp. 321-334). New York: Routledge.

Hayes, A. F., \& Matthes, J. (2009). Computational procedures for interaction in OLS and logistic regression: SPSS and SAS implementations. Behavior Research Methods, 41, 924-936. doi:10.3758/BRM.41.3.924

Johnson, D. (2006). Crime salience, perceived racial bias, and Blacks' punitive attitudes. Journal of Ethnicity in Criminal Justice, 4, 1-18. doi:10.1300/J222v04n04 01

Johnson, D. (2008). Racial prejudice, perceived injustice, and the Black-White gap in punitive attitudes. Journal of Criminal Justice, 36, 198-206. doi:10.1016/j.jcrimjus.2008.02.009

Johnson, P. O., \& Neyman, J. (1936). Tests of certain linear hypotheses and their applications to some educational problems. Statistical Research Memoirs, 1, 115-134.

Kaminer, D., Stein, D. J., Mbanga, I., \& Zungu-Dirwayi, N. (2001). The Truth and Reconciliation Commission in South Africa: Relation to psychiatric status and forgiveness among survivors of human rights abuses. British Journal of Psychiatry, 178, 373-377. doi:10.1192/bjp.178.4.373

Mania, E. W. (2009). The intergroup dynamics of responding to transgression: An examination of racial biases and disparities in responding to wrongdoers. Doctoral Thesis, ProQuest Dissertations and Theses Database, UMI No. 3373307.

McCullough, M. E., Rachal, K. C., Sandage, S. J., Worthington, E. L., Jr., Brown, S. W., \& Hight, T. L. (1998). Interpersonal forgiving in close relationships: II. Theoretical elaboration and measurement. Journal of Personality and Social Psychology, 75, 1586-1603. doi: 10.1037/0022-3514.75.6.1586

McCullough, M. E., Root, L. M., \& Cohen, A. D. (2006). Writing about the benefits of an interpersonal transgression facilitates forgiveness. Journal of Consulting and Clinical Psychology, 74, 887-897. doi:10.1037/0022-006X.74.5.887

Miller, D. T. (2001). Disrespect and the experience of injustice. Annual Review of Psychology, 52, 527-553. doi:10.1146/annurev.psych.52.1.527

Quinney, R. (1970). The social reality of crime. Boston, MA: Little, Brown.

Schultz, J. M., Tallman, B. A., \& Altmaier, E. M. (2010). Pathways to posttraumatic growth: The contributions of forgiveness and importance of religion and spirituality. Psychology of Religion and Spirituality, 2, 104-114. doi:10.1037/a0018454

Stein, D. J., Seedat, S., Kaminer, D., Moomal, H., Herman, A., Sonnega, J., \& Williams, D. R. (2008). The impact of the Truth and Reconciliation Commission on psychological distress and forgiveness in South Africa. Social Psychiatry and Psychiatric Epidemiology, 43, 462-468. doi: 10.1007/s00127-008-0350-0

Sue, D. W., Capodilupo, C. M., Torino, G. C., Bucceri, J. M., Holder, A. M. B., Nadal, K. L., \& Esquilin, M. (2007). Racial microaggressions in everyday life: Implications for clinical practice. American Psychologist, 62, 271-286. doi:10.1037/0003-066X.62.4.271

Suwartono, C., Praswasti, C. Y., \& Mullet, E. (2007). Effect of culture on forgivingness: A Southern Asia-Western Europe comparison. Personality and Individual Differences, 42, 513-523. doi:10.1016/j.paid.2006.07.027

Truth and Reconciliation Commission (2003). Final report of the South African Truth and Reconciliation Commission. URL (last checked 20 January 2011) http://www.info.gov.za/otherdocs/2003/trc/

Wade, N. G., Worthington, E. L. Jr., \& Meyer, J. E. (2005). But do they work? A meta-analysis of group interventions to promote forgiveness. In E. L. Jr. Worthington, (Ed.), Handbook of forgiveness (pp. 423-439). New York, NY: Routledge.

Weiss, D. S., \& Marmar, C. R. (1997). The impact of event scaleRevised. In J. P. Wilson, \& T. M. Keane (Eds.), Assessing psychological trauma and PTSD (pp. 399-411). New York, NY: Guilford Press.

Witvliet, C. V., Knoll, R. W., Himnan, N. G, \& DeYoung, P. A. (2010). Compassion-focused reappraisal, benefit-focused reappraisal, and rumination after an interpersonal transgression: Emotion-regulation implications for subjective emotion, linguistic responses, and physiology. Journal of Positive Psychology, 5, 226-242. doi:10.1080/17439761003790997 